This item was submitted to Loughborough's Research Repository by the author.

Items in Figshare are protected by copyright, with all rights reserved, unless otherwise indicated.

\title{
pH-responsive chiral nanostructures
}

PLEASE CITE THE PUBLISHED VERSION

http://dx.doi.org/10.1071/CH11131

PUBLISHER

(C) CSIRO

\section{VERSION}

AM (Accepted Manuscript)

\section{PUBLISHER STATEMENT}

This work is made available according to the conditions of the Creative Commons Attribution-NonCommercialNoDerivatives 4.0 International (CC BY-NC-ND 4.0) licence. Full details of this licence are available at: https://creativecommons.org/licenses/by-nc-nd/4.0/

\section{LICENCE}

CC BY-NC-ND 4.0

\section{REPOSITORY RECORD}

Du, Jianzhong, Helen Willcock, Nga Sze leong, and Rachel K. O'Reilly. 2016. "Ph-responsive Chiral Nanostructures". figshare. https://hdl.handle.net/2134/22887. 


\title{
pH-responsive chiral nanostructures
}

\author{
Jianzhong Du, ${ }^{a, b}$ Helen Willcock, ${ }^{a}$ Nga Sze leong ${ }^{a}$ and Rachel K. O'Reilly ${ }^{a,{ }^{*}}$
}

${ }^{a}$ University of Warwick, Department of Chemistry, Gibbet Hill Road, Coventry, CV7 4AL, UK. Fax: +44

(024) 765 24112; Tel: +44 (0)247 652 3236; E-mail: R.K.O-Reilly@warwick.ac.uk.

${ }^{b}$ Current address: School of Materials Science and Engineering, Tongji University, 1239 Siping Road, Shanghai, China.

\begin{abstract}
There is great current interest in the design of robust synthetic polymers for the preparation of novel functional, well-defined, biocompatible and tailorable materials for a range of applications. In this work we have used reversible addition fragmentation chain transfer (RAFT) polymerization to prepare chiral and responsive amphiphilic block copolymers (based on polyphenylalanine acrylamide) which can be assembled at different pHs to form well-defined nanostructures, whose morphology and size were explored using TEM, DLS and SLS measurements and stability by fluorescence and NMR spectroscopy.
\end{abstract}


The application of these chiral and responsive nanostructures in the resolution of hydrophilic racemic amino acids has also been explored.

\section{Introduction}

The preparation of responsive and functional nanostructures for applications as smart materials is an area of great interest in polymer science.(1-4) In particular recent advances in controlled radical polymerization (CRP) techniques have allowed for the preparation of a wide range of well-defined and functional polymers, thus affording readily tunable structural and chemical features.(5-10) Of particular interest is the development of responsive or smart materials that respond (for example through a change in solubility) to external stimuli.(11-13) There are a number of stimuli which can be used to afford a change in polymer properties including most commonly temperature, light, oxidation and $\mathrm{pH} .(14-18)$ A wide range of new polymers have been prepared and explored as responsive materials with particular interest in the development of block copolymers which display dual responsive properties.(19) Of further interest are schizophrenic systems which were first reported by Armes and coworkers. $(20,21)$ These systems offer an additional level of control and allow for the inversion of nanostructure domains and a change in overall nanostructure properties. For example, in 2009 we reported the preparation of a schizophrenic responsive diblock whose surface charge could be inverted by changing the $\mathrm{pH}$ of the solution.(22) It was proposed that this feature could be key in the preparation of functional nanostructures for selective encapsulation, interaction and release. Furthermore the introduction of additional functionality into these systems is of great interest as is the preparation of novel solution assembly morphologies to allow for access to highly complex nanostructures for utilization in a range of applications as nanoreactors and delivery vehicles. In recent years there has 
been increasing interest in the development of new polymeric materials which can undergo selective assembly to form non-spherical morphologies including cylinders, toroids and discs.(23) The application of these non-spherical morphologies has not yet been fully realized, however the potential of cylindrical structures in advanced drug delivery applications has recently been reported. (24)

The groups of Endo, Mori and coworkers have pioneered the area of poly(amino acids) over the last 15 years.(25) This group have utilized both conventional radical techniques and also more recently CRP for the synthesis of a range of poly(amino acids). Compared to the sequential amidation reactions which are used in polypeptide formation often only the amino group is utilized in the coupling to the vinyl functionality leaving the acid (or often protected acid) group available along the polymer side chain. This can impart important solubility characteristics to the polymer and also provide a useful handle for further functionalization. We are interested in the preparation and properties of vinyl amino acid polymers which can possess a number of key features including chirality and catalytic activity which can exploited in the preparation of novel functional nanostructures. Furthermore we are interested in using readily accessible controlled radical techniques for the preparation of multiblocks and assemblies of these amino acid based polymers.(26-29) In particular our interest in this class of polymers was based on the elegant work of Endo and Sanda who have been demonstrated their temperature and pH responsivity. $(26,30)$ In this work we hoped to explore the further application of these chiral and pH responsive polymers for $\mathrm{pH}$ controlled self assembly to afford non-spherical responsive nanostructures that may find application as media for chiral separations.

\section{Results and Discussion}


To prepare poly (vinyl amino acid) block copolymers we utilized reversible addition fragmentation chain transfer (RAFT) polymerization given its tolerance to carboxylic acid functionality, ready end group modification and also precedent in the direct polymerization of acid functionalized amino acid monomers.(31) Hence, using established RAFT polymerization methods we prepared a chiral diblock copolymer by first polymerizing diaminoethyl methacrylate (DEA) using $S^{\prime}$-1-dodecyl-(S')-( $\alpha, \alpha^{\prime}$-dimethyl$\alpha^{\prime \prime}$-acetic acid) trithiocarbonate (DDMAT), as an initiator to afford PDEA, $1\left(M_{n}=14.1 \mathrm{kDa}, \mathrm{M}_{\mathrm{w}} / \mathrm{M}_{\mathrm{n}}=\right.$ 1.34). This macro-CTA could then be extended using L-phenylalanine acrylamide (PAP) in DMF (Scheme 1) using 4,4'-azobis(4-cyanovaleric acid) (ACA) as an initiator to afford block copolymer 2 . This initiator was chosen given its slower rate of decomposition compared to AIBN and this was found to allow for more efficient block copolymer synthesis. This diblock was characterized by both GPC and NMR analysis $\left(M_{n}(G P C, T H F)=32.8 \mathrm{kDa}, M_{w} / M_{n}=1.19\right.$ and $\left.M_{n}(N M R)=30.7 \mathrm{kDa}\right)$ which confirm the preparation of the desired block copolymer, $\mathrm{PDEA}_{76}-\mathrm{b}-\mathrm{PAP}_{76}$, with intact end groups.

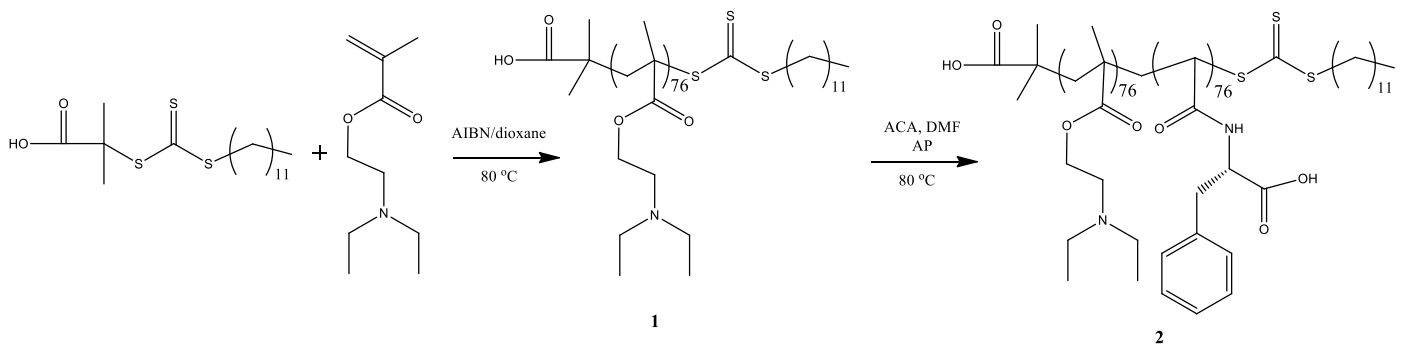

Scheme 1 Synthesis of amphiphilic diblock 2 using RAFT polymerization.

This diblock could be directly dissolved (at $0.2 \mathrm{mg} / \mathrm{ml})$ at both low $(\mathrm{pH}=2)$ and high $\mathrm{pH}(\mathrm{pH}=$ 12), however at neutral $\mathrm{pH}$ it was not fully soluble, to afford well-defined nanostructures. The selective solubility of both blocks at different pHs was confirmed by ${ }^{1} \mathrm{H}$ NMR spectroscopy (Figure 1) in a range of solvents. From Figure 1 it was confirmed as expected at low pH the PAP block will be hydrophobic (as determined by the absence of characteristic aromatic signals in the ${ }^{1} \mathrm{H}$ NMR spectrum) and the PDEA 
block will be protonated and hence be hydrophilic. Given these observations at low $\mathrm{pH}$ and given the lengths of both blocks (with a hydrophilic weight fraction of $46 \%$ ) a spherical or cylindrical morphology would be predicted based on established self assembly principles. At high $\mathrm{pH}$ given the length of both blocks and a hydrophilic weight fraction of $54 \%$ a spherical morphology would be predicted. However, we were interested to explore if the hydrophobic RAFT end group affected the assembly of these diblocks at different $\mathrm{pH}$.

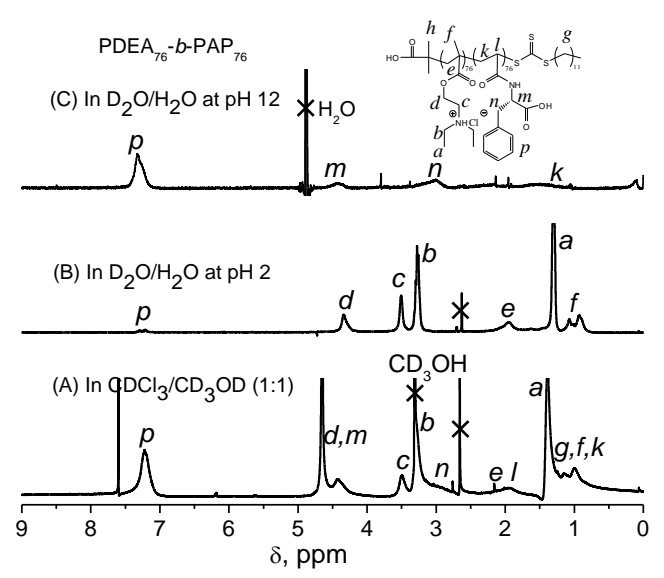

Fig. 1. ${ }^{1} \mathrm{H}$ NMR spectra of $P D E A_{76}-b-P A P P_{76}, 2:(A)$ in $\mathrm{CDCl}_{3} / \mathrm{CD}_{3} \mathrm{OD}(1: 1)$, a good solvent mixture for both blocks; (B) in $\mathrm{D}_{2} \mathrm{O} / \mathrm{H}_{2} \mathrm{O}(1: 9)$ at $\mathrm{pH}$ 2, the peaks from PDEA are visible whereas peaks assigned to PAP (such as $p$ and $n$ ), and peaks assigned to DDMAT (g) are attenuated; $(C)$ in $\mathrm{D}_{2} \mathrm{O} / \mathrm{H}_{2} \mathrm{O}(1: 9)$ at $\mathrm{pH} 12$, peaks from PAP (such as $p$ and $n$ ) are visible whereas peaks from PDEA ( $a, b, d, e$, and f) are attenuated.

Dynamic light scattering (DLS) analysis indicated large relatively well-defined particles ca. 197 $\mathrm{nm}$ (PD 0.119), at low pH (solution concentration $0.2 \mathrm{mg} / \mathrm{ml}$ ) which could not be spherical micelles based on the maximum stretching of the chains, hence TEM analysis was used to confirm the morphology of these nanostructures. Using TEM analysis (without staining) a cylindrical morphology was 
confirmed, with diameters around $40 \mathrm{~nm}$ (Figure 2). Furthermore static light scattering (SLS) in combination with DLS data, using Zimm plot analysis confirmed a rod-like morphology with $R_{g} / R_{h}=1.93$ which is close to the theoretical value of 2 . At low $\mathrm{pH}$ we propose the PDEA forms the coronal domain and is protonated and this was confirmed by zeta potential analysis (+33 mV). From previous work we are confident that the trithiocarbonate hydrophobic end group does not undergo hydrolysis and is intact at the $\omega$-end of the chains. Attempts to assemble this polymer at higher concentrations afforded similar results although the distribution of sizes as observed by DLS increased upon increasing polymer concentration.

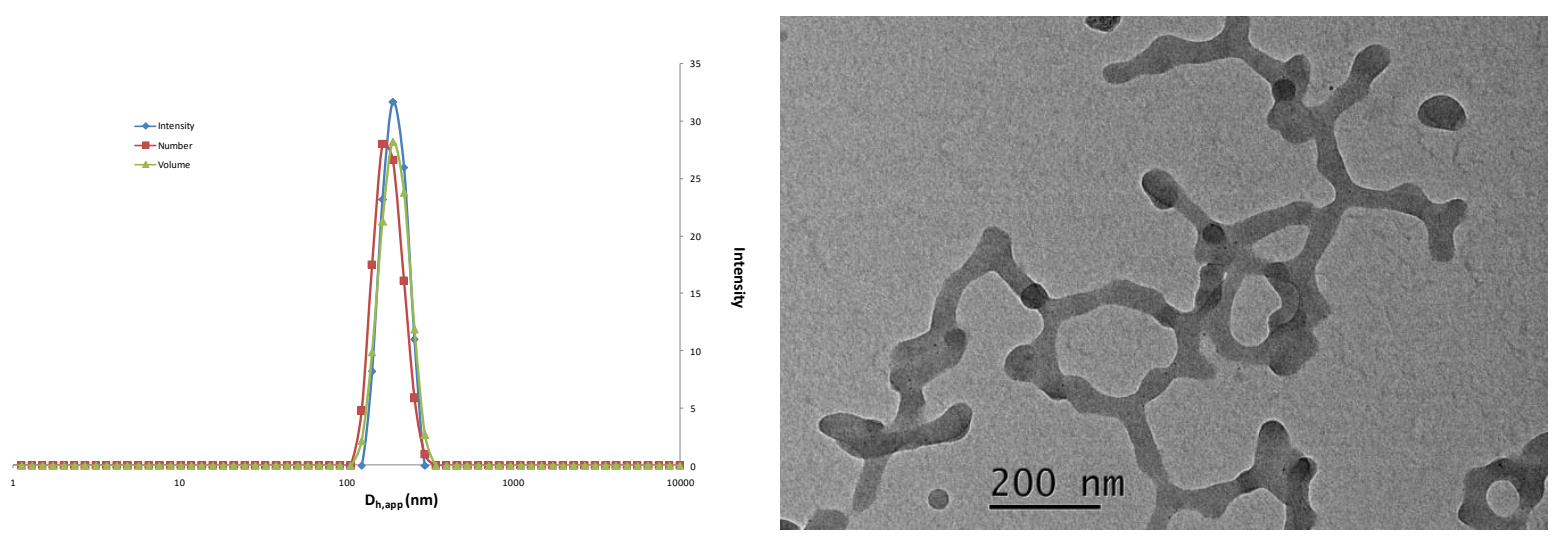

Fig. 2 DLS (LHS) and TEM (RHS) analysis (with no staining) of diblock 2 self-assembled at $0.2 \mathrm{mg} / \mathrm{ml}$ at low $\mathrm{pH}$.

The assembly of this polymer $\mathbf{2}$ at high $\mathrm{pH}$ was also explored (at $0.2 \mathrm{mg} / \mathrm{ml}$ ) and by DLS analysis nanostructures of ca. $57 \mathrm{~nm}$ (PD 0.219) were observed. Furthermore zeta potential analysis of this solution confirmed a negative surface charge $(-40 \mathrm{mV})$ indicating a PAP corona, as expected based on the hydrophilicity of the PAP block. Further analysis by TEM (staining with uranyl acetate) indicated relatively ill-defined spherical particles were formed which agrees with the predicted structure based on 
ca. $54 \%$ hydrophilic weight fraction. Further analysis by cryo-TEM confirmed that spherical structures of ca. $26 \mathrm{~nm}$ were formed, which appeared to be micelles, although were rather disperse (Figure 3). We also investigated the angular dependence of the aggregate size of both solutions by DLS and as expected for non-spherical particles at low pH a strong dependence of diffusion coefficient was observed at a range of q values. Interestingly at high $\mathrm{pH}$ some dependence was observed with indicates that these particles are also anisotropic (Figure 4). SLS analysis of this assembly at high pH were inconclusive due to large errors in the Zimm plot analysis as a result of the broad dispersity of the assembly.

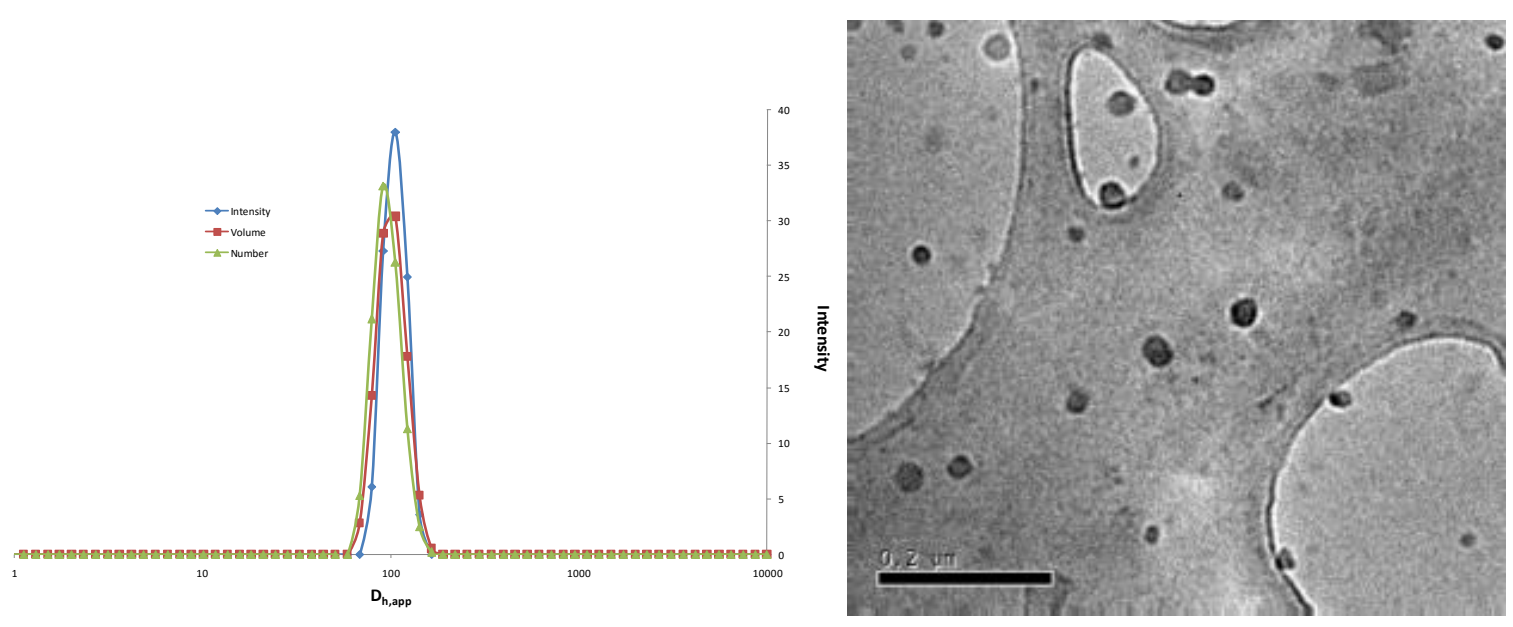

Fig. 3 DLS (LHS) and cryo-TEM (RHS) analysis of diblock 2 self-assembled at $0.2 \mathrm{mg} / \mathrm{ml}$ high pH.

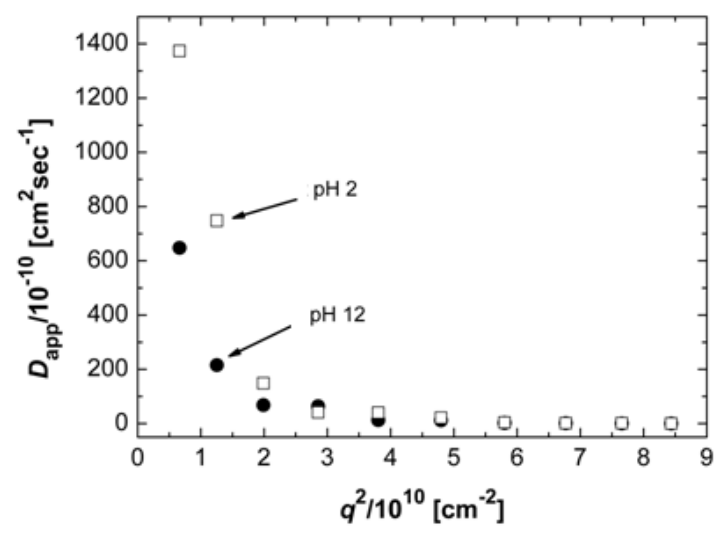

Fig. 4 Angular dependent size for polymer 2 assembled at $\mathrm{pH}=2$ and $\mathrm{pH}=12$. 
We also explored the solution properties of these polymers and determined the critical micelle concentration (cmc) of both nanostructures using $N$-phenyl-1-naphthylamine (PNA) as a probe. PNA has recently been proposed to be an improved probe for the $\mathrm{cmc}$ determination of amphiphiles given its robust nature and also stronger shift in absorbance compared to pyrene.(32) From this it was clear that the assembly at low $\mathrm{pH}$ had an order of magnitude higher $\mathrm{cmc}$ value compared to the assembly at high $\mathrm{pH}\left(3.16 \times 10^{-3}\right.$ compared to $\left.1.78 \times 10^{-2} \mathrm{~g} / \mathrm{L}\right)$, although both values were close to reported $\mathrm{cmc}$ values for diblock copolymer assemblies. This provides an interesting responsive feature of these systems as altering the $\mathrm{pH}$ changes dramatically changes the $\mathrm{cmc}$ of the aggregate hence allowing for the tuned dissolution and reassembly at different $\mathrm{pH}$ and also concentrations. Indeed we observed by DLS after extended periods of time the samples prepared at low $\mathrm{pH}$ were stable, however at high $\mathrm{pH}$ the assemblies were not.

We explored increasing the solution $\mathrm{pH}$ of the aggregates formed at $\mathrm{pH} 2$ through to $\mathrm{pH} 14$ and through to $\mathrm{pH} 2$ again, to examine the reversibility of the transition. We observed upon increasing the pH the size decreased slightly (to ca. $171 \mathrm{~nm}$ at $\mathrm{pH}$ 6) and at ca. $\mathrm{pH}$ 7-9 precipitation of the solution occurred, which prevented facile cycling between extremes of $\mathrm{pH}$. However, the aggregates could be reformed by further increasing the solution $\mathrm{pH}$, however a broad distribution of particles (PD ca. 0.41) were obtained, indicating less well-defined aggregates were formed. 


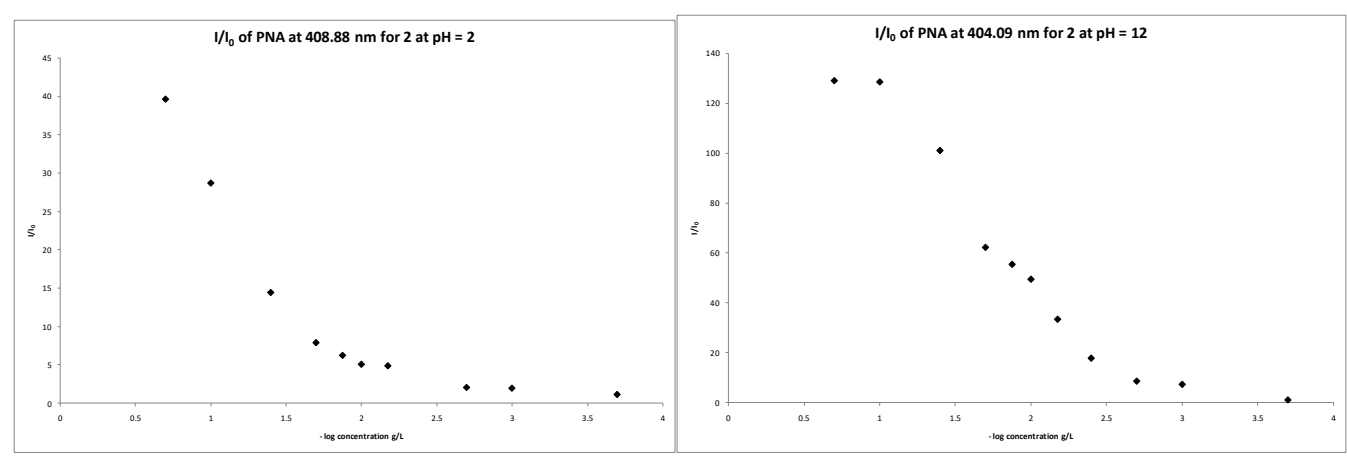

Fig 5 Plots to determine the $\mathrm{cmc}$ for polymer 2 assembled at $\mathrm{pH}=2$ (LHS) and $\mathrm{pH}=12$ (RHS).

We propose at high $\mathrm{pH}$ it is known that the RAFT trithiocarbonate end group can be readily hydrolyzed and hence the assembly at high $\mathrm{pH}$ (and $0.2 \mathrm{mg} / \mathrm{ml}$ ) was repeated with polymer $\mathbf{2}$ which had undergone end group removal using established methods.(33) Using this new polymer 2' we observed very similar sized nanostructures, at low pH by DLS (174 nm, PD 0.126) as previously observed for polymer $\mathbf{2}$ which contained the RAFT end group. However, assembly of $\mathbf{2}^{\prime}$ at high pH afforded much larger assemblies by DLS analysis (104 nm, PD 0.114). Furthermore upon ${ }^{1} \mathrm{H}$ NMR analysis of the polymer $\mathbf{2}$ after assembly at high pH after 1 month the end groups were no longer visible indicating that under these conditions the end groups are not stable.

We have recently reported that the phenylalanine methyl ester amino acid polymer can be utilized as a substrate for chiral enhancement due to the increased interaction between opposite enantiomers.(34) In this work we wanted to explore this interaction further using our new water soluble phenylalanine polymer (PAP). We proposed that at low $\mathrm{pH}$ when the PAP block is hydrophobic, there should be a stronger interaction with the opposite enantiomer compared to at high $\mathrm{pH}$ when the polymer is hydrophilic. Interestingly in this system we observed little recognition between enantiomeric pairs (L-PAP in our nanostructure and D-PAP in solution) compared to our previously reported system. 
This may be in part due to the deprotonation of the PAP at low $\mathrm{pH}$ which prevent recognition and also highlights that a hydrophobic environment appears to be key to exploit recognition in the particles.

\section{Experimental Section}

\section{Materials}

All the reagents were purchased from Aldrich and used as received. Dialysis tubing was purchased from Medicell International Ltd with a molecular weight cut-off of 1 kDa. DDMAT (S'-1-dodecyl-(S')-( $\alpha, \alpha^{\prime}-$ dimethyl- $\alpha^{\prime \prime}$-acetic acid) trithiocarbonate) was synthesized according to the reported procedures.(35)

\section{Characterization}

The molecular weight distributions of polymers were assessed at $40^{\circ} \mathrm{C}$ using a Polymer Laboratories PLGPC50 Integrated GPC system equipped with a Polymer Laboratories micro-volume double piston pump (approx. $10 \mu \mathrm{L}$ per stoke), a PLgel $5 \mu \mathrm{m}$ MIXED-D column $(300 \times 7.5 \mathrm{~mm})$, and a refractive index detector. The calibration was carried out using ten polystyrene standards with $M_{p}$ values ranging from 580 to $377,400 \mathrm{Da}$. The eluent was THF containing $2.0 \%(\mathrm{v} / \mathrm{v})$ TEA and $0.05 \%(\mathrm{w} / \mathrm{v}) \mathrm{BHT}$ and the flow rate was $1.0 \mathrm{~mL} / \mathrm{min}$. The data were processed using Cirrus GPC offline GPC/SEC software. ${ }^{1} \mathrm{H}$ NMR spectra were recorded using a Bruker AV $400(400 \mathrm{MHz})$ spectrometer at ambient temperature using either $\mathrm{CDCl}_{3}, \mathrm{CD}_{3} \mathrm{OD}, \mathrm{CD}_{3} \mathrm{OD} / \mathrm{CDCl}_{3}, \mathrm{D}_{2} \mathrm{O} / \mathrm{H}_{2} \mathrm{O}$ or $\mathrm{D}_{2} \mathrm{O}$ as solvents. TEM images were obtained using a JEOL electron microscope operating at 200 kV equipped with a LaB6 gun and a Gatan digital camera. Freshly prepared aqueous $1.0 \%$ uranyl acetate solution was used to stain the nanostructures. The averaged size of vesicles was calculated based on examining at least fifty particles from at least six different TEM images. Cryo-TEM was performed on a Jeol 2010F TEM (200 kV FEG) with 4K Gatan Ultrascan camera 
and cryo capability. Zeta potential and DLS studies were conducted at $25^{\circ} \mathrm{C}$ using a Zetasizer Nano series instrument (Malvern Instruments). DLS studies of aqueous aggregates were conducted over a range of solution $\mathrm{pHs}$ at a fixed scattering angle of $173^{\circ}$. The data were processed by Cumulants analysis of the experimental correlation function and aggregate diameters were calculated from the computed diffusion coefficients using the Stokes-Einstein equation. Each reported measurement was the average of three runs. SLS studies were performed at $25^{\circ} \mathrm{C}$ using a Malvern Autosizer 4800 Instrument. To produce the Zimm plot 20 angles between 30 to $150{ }^{\circ} \mathrm{C}$ and 5 different concentrations of micelle solution were scanned and included in the calculation.

\section{Synthesis of CTA and Polymers}

Polymer $1\left(\right.$ PDEA $\left._{76}\right)$ was synthesized to afford the macro-CTA for polymer 2 . In a typical RAFT protocol, a flask with a magnetic stirrer bar and a rubber septum was charged with AIBN radical initiator (3.0 mg; $3.3 \times 10^{-2} \mathrm{mmol}$ ), DDMAT CTA (94.0 mg; $0.162 \mathrm{mmol}$ ), DEA monomer (3.04 g; $16.2 \mathrm{mmol}$ ) and dioxane (8.12 $\mathrm{mL}$ ). This solution was deoxygenated using a $\mathrm{N}_{2}$ purge for 30 minutes before heating at $80{ }^{\circ} \mathrm{C}$ under a nitrogen atmosphere. The [DEA]: [DDMAT]: [AIBN] relative molar ratios were 100:1:0.2. After $4.5 \mathrm{~h}$ the monomer conversion was calculated to be $76 \%$ by ${ }^{1} \mathrm{H}$ NMR spectroscopy. The final polymerization solution was diluted with acetone and $0.01 \mathrm{M} \mathrm{HCl}$ aqueous solution and then purified by dialysis against water at pH 2-4. A fine white powder was obtained after freeze-drying. ${ }^{1} \mathrm{H}$ NMR spectra are shown in the manuscript $\left(M_{n}(N M R)=14.7 \mathrm{kDa}\right)$. THF GPC: $M_{n}=16.5 \mathrm{kDa} ; \mathrm{M}_{\mathrm{w}} / \mathrm{M}_{\mathrm{n}}=1.7$.

In a typical RAFT protocol, a flask with a magnetic stirrer bar and a rubber septum was charged with ACA radical initiator ( $2 \mathrm{mg} ; 7.0 \times 10^{-3} \mathrm{mmol}$ ), protonated PDEA 76 macro-CTA ( $244 \mathrm{mg} ; 1.4 \times 10^{-2}$ $\mathrm{mmol})$, AP monomer (316 mg; $1.4 \mathrm{mmol}$ ) and DMF $(8 \mathrm{~mL})$. This solution was deoxygenated using a $\mathrm{N}_{2}$ 
sparge for 30 minutes before heating at $80^{\circ} \mathrm{C}$ under a nitrogen atmosphere. The [AP]: [PDEA76]: [ACA] relative molar ratios were 100:1:0.5. After $27 \mathrm{~h}$ reaction was purified by precipitation in ethyl acetate to form a white precipitate. THF GPC: $M_{n}=19.7 \mathrm{kDa} ; \mathrm{M}_{\mathrm{w}} / \mathrm{M}_{\mathrm{n}}=1.27$. By ${ }^{1} \mathrm{H} N M R, \mathrm{M}_{n}=27.1 \mathrm{kDa}$.

\section{Preparation and characterization of aggregates}

Block copolymer $2(100 \mathrm{mg})$ was dissolved into $100 \mathrm{~g}$ pure water at $\mathrm{pH} 2$ at $80{ }^{\circ} \mathrm{C}$ for several minutes to form aggregates directly, then stirred at room temperature. At pH 12, the solution needed to be stirred for several hours to afford a clear blue nanostructure solution. The assemblies were characterized by ${ }^{1} \mathrm{H}$ NMR spectroscopy. After four months, the initial nanostructures still exists at $\mathrm{pH} 2$ but do not exist at $\mathrm{pH}$ 12 , as a result of different stabilities of trithiocarbonate groups in the vesicle membrane at low (stable) and high $\mathrm{pH}$ (unstable). The resultant aggregates were characterized by DLS at different $\mathrm{pH}$ values and the correlation functions fit well with the Cumulants analysis and the intensity-averaged vesicle size distributions are reasonably consistent with number and volume averaged size distributions. The resultant vesicles were stained and viewed by TEM and cryo TEM.

\section{Chiral resolution studies}

Using the procedures described previously,(36) we explored the chiral recognition of our phenylalanine nanostructures at both low and high $\mathrm{pH}$. The nanostructures $(2 \mathrm{ml}$ of solution of concentration 0.2 $\mathrm{mg} / \mathrm{ml}$ ) were incubated overnight with D-phenylalanine. After this time the micelle solution was transferred to an ultrafiltration cell (MWCO $3.5 \mathrm{kDa}$ ) and $c a .0 .5 \mathrm{~mL}$ of solute was collected. The 
resulting solutions were analyzed by polarimetry and the reaction had a specific rotation that was close to zero which corresponds to the original racemic solution.

\section{Conclusions}

We have shown a new class of amphiphilic and $\mathrm{pH}$ responsive polymers based on chiral vinyl amino acids, prepared by RAFT polymerization which can assemble into well-defined nanostructures. We have highlighted the versatility of this diblock system towards the assembly of non-spherical morphologies and also the importance of end group on the resultant morphology. Disappointingly these chiral nanostructures did not display chiral resolution abilities, however further work is expanding the scope of these systems towards the design of functional and responsive nanostructures.

\section{Acknowledgements}

The authors thank the EPSRC, the Royal Society, the Leverhulme Trust and the University of Warwick for funding. Dr Steve Furzeland from Unilever is thanked for cryo-TEM analysis. Some of the equipment used in this research was obtained, through Birmingham Science City with support from Advantage West Midlands (AWM) and part funded by the European Regional Development Fund (ERDF).

\section{References}


1. Li M-H, Keller P. Soft Matter. 2009;5:927.

2. Du J, O'Reilly RK. Soft Matter. 2009;5:3544.

3. Read ES, Armes SP. Chem Commun. 2007:3021.

4. O'Reilly RK, Hawker CJ, Wooley KL. Chem Soc Rev. 2006;35:1068.

5. Hawker CJ. Acc Chem Res. 1997;30:373.

6. Moad G, Rizzardo E, Thang SH. Aust J Chem. 2005;58:379.

7. Perrier S, Takolpuckdee P. J. Polym. Sci. Part A: Polym. Chem. 2005;43:5347.

8. Matyjaszewski K, Xia J. Chem Rev. 2001;101:2921.

9. Moad G, Rizzardo E, Thang SH. Aust J Chem. 2006;59:669.

10. Moad G, Rizzardo E, Thang SH. Polymer. 2008;49:1079.

11. Alexander C, Shakesheff KM. Adv Mater,. 2006;18:3321.

12. Schmaljohann D. Adv Drug Delivery Rev. 2006;58:1655.

13. Dai S, Ravi P, Tam KC. Soft Matter. 2008;4:435.

14. Yuting L, Brad SL, Charles LM. Angew Chem Int Ed. 2006;45:5792.

15. Du J, Tang Y, Lewis AL, Armes SP. J Am Chem Soc. 2005;127:17982.

16. Napoli A, Valentini M, Tirelli N, Muller M, Hubbell JA. Nature Mater. 2004;3:183.

17. Tang X, Cao L, Fan X, Liang X, Zhou Q. Macromol Chem Phys. 2009;210:1556.

18. Pietsch C, Hoogenboom R, Schubert US. Angew Chem Int Ed. 2009;48:5653.

19. Chang C, Wei H, Feng J, Wang Z-C, Wu X-J, Wu D-Q, et al. Macromolecules. 2009;42:4838.

20. Liu S, Billingham NC, Armes SP. Angew Chem Int Ed. 2001;40:2328.

21. Liu S, Armes SP. Angew Chem Int Ed. 2002;41:1413.

22. Du J, O'Reilly RK. Macromol Chem Phys. 2010;211:1530.

23. Holder S, Sommerdijk NAJM. Polym Chem. 2011;2:DOI: 10.1039/c0py00379d.

24. Geng Y, Dalhaimer P, Cai SS, Tsai R, Tewari M, Minko T, et al. Nature Nano. 2007 Apr;2:249.

25. Sanda F, Endo T. Macromol Chem Phys. 1999;200:2651.

26. Mori H, Iwaya H, Nagai A, Endo T. Chem Commun. 2005:4872.

27. Casolaro M, Paccagnini E, Mendichi R, Ito Y. Macromolecules. 2005;38:2460.

28. Skey J, O'Reilly RK. J. Polym. Sci. Part A: Polym. Chem. 2008;46:3690.

29. O'Reilly RK. Polym Inter. 2010;59:586.

30. Mori H, Matsuyama M, Sutoh K, Endo T. Macromolecules. 2006;39:4351.

31. Lowe AB, McCormick CL. Prog Polym Sci. 2007;32:283.

32. Xu P, Tang H, Li S, Ren J, Van Kirk E, Murdoch WJ, et al. Biomacromolecules. 2004;5:1736.

33. Willcock H, O'Reilly RK. Polym Chem. 2011;1:149.

34. Skey J, Willcock H, Lammens M, du Prez F, O'Reilly RK. Macromolecules. 2010;43:5949.

35. Skey J, O'Reilly RK. Chem Commun. 2008:4183.

36. Skey J, Hansell CH, O'Reilly RK. Macromolecules. 2010;43:1309. 